\title{
1 Bright moonlight triggers natal dispersal departures
}

2

3 Vincenzo Penteriania ${ }^{\mathrm{a}, \mathrm{e}}$, María del Mar Delgado ${ }^{\mathrm{b}}$, Anna Kuparinen ${ }^{\mathrm{c}, \mathrm{d}}$, Pertti Saurola ${ }^{\mathrm{e}}$, Jari

$4 \quad$ Valkama $^{\mathrm{e}}$, Eino Salof ${ }^{\mathrm{f}}$ Jere Toivola ${ }^{\mathrm{g}}$, Adrian Aebischer ${ }^{\mathrm{h}}$ and Raphaël Arlettaz ${ }^{\mathrm{h}}$

5

6 a Department of Conservation Biology, Estación Biológica de Doñana, C.S.I.C., cl Americo

$7 \quad$ Vespucio s/n, 41092 Seville, Spain

8

$9 \quad{ }^{b}$ Metapopulation Research Group, Department of Biosciences, University of FI-00014 Helsinki,

10 Finland

11

$12{ }^{c}$ Department of Environmental Sciences, ${ }^{d}$ Department of Biosciences, University of Helsinki,

13 FI-00014 Helsinki, Finland

14

$15{ }^{e}$ Finnish Museum of Natural History, Zoology Unit, University of Helsinki, FI-00014

16 Helsinki, Finland

17

18

f Paloniityntie 90, Forssa, Finland

19

20

21

22

23

${ }^{g}$ Taatilantie 74, Tarttila, Finland

${ }^{h}$ Division of Conservation Biology, Institute of Ecology and Evolution, University of Bern, Baltzerstrasse 6, 3012 Bern, Switzerland

24

25

26 Corresponding author: Vincenzo Penteriani, Department of Conservation Biology,

27 Estación Biológica de Doñana, C.S.I.C., c/ Americo Vespucio s/n, 41092 Seville, SPAIN.

28 E-mail: penteriani@ebd.csic.es 


\section{ABSTRACT}

30 Upon leaving their natal area, dispersers are confronted with unknown terrains. Species-specific

31 perceptual ranges (i.e., the maximum distance from which an individual can perceive landscape

32 features) play a crucial role in spatial movement decisions during such wanderings. In nocturnal

33 animals that rely on vision, perceptual range is dramatically enhanced during moonlight, compared

34 to moonless conditions. This increase of the perceptual range is an overlooked element that may be

35 responsible for the successful crossing of unfamiliar areas during dispersal. The information

36 gathered from 143 radio-tagged eagle owl Bubo bubo juveniles in Spain, Finland and Switzerland

37 shows that, although the decision to initiate dispersal is mainly an endogenous phenomenon

38 determined by the attainment of a given age ( -6 months), dispersers leave their birthplace primarily

39 under the best light conditions at night, i.e. when most of the lunar disc is illuminated. This sheds

40 new light into the mechanisms that may trigger dispersal from parental territory.

41

42 Keywords: dispersal age, lunar cycle, moon phase, perceptual range, timing of dispersal, visual cues,

43 Bubo bubo

44

45 Word count: 3808 


\section{INTRODUCTION}

47 The start of natal dispersal represents a risky stage in the life of animals, which entails

48 multiple costs (Bonte et al. 2012). Consequently, when the time comes to leave the

49 birthplace, individuals are expected to start their dispersal under the best conditions.

50 Visual cues are crucial for animals moving at night; for instance, many migratory

51 birds refer to moonlight position to establish and maintain orientation during their nocturnal journey (Martin 1990). The lunar cycle (full moon to full moon, 29.5 days)

53 determines important environmental changes that influence and can be perceived by

54 animals. Night-time light levels are far from uniform: around full moon, the increased light levels at night may determine the occurrence of occasional nocturnal activities (like night

56 foraging and migration) in otherwise strictly diurnal birds (Pienkowski 1982; Martin 1990;

57 Bulyuk et al. 2009). Nocturnal birds also benefit from the additional light provided by a completely, or nearly, full moon (Martin 1990; Brigham and Barclay 1992): night-time movements and feeding appear to be enhanced by moonlight, independent of the visual sensitivity of owls and other nocturnal birds. Thus, although there are certainly many more favourable conditions than those provided by moonlight, the lunar light has the potential to represent an important factor affecting nocturnal movement across unknown landscapes. The perceptual range of animals, i.e. the maximum distance from which an individual can perceive landscape features and elements, plays an important role in spatial processes (Zollner and Lima 1997). The perceptual range affects movement strategies and behaviours during dispersal, as well as the probability of successfully reaching suitable

67 habitats (Lima and Zollner 1996; Zollner and Lima 1999). For nocturnal species, the 
and Lima 1999): their perceptual abilities increase as ambient illumination increases, even

though they have considerable visual acuity (Zollner and Lima 1999). It remains poorly understood to which extent moonlight phases may interfere with spatial movement decision such as natal dispersal in nocturnal species.

Here, we show that a nocturnal avian predator, the eagle owl Bubo bubo, starts dispersal primarily when juveniles are -6 months old and the ambient light is the most favourable for perceiving and exploring unfamiliar lands. This phenomenon occurs within its whole distribution range, as demonstrated here by eagle owl natal dispersal in three geographically and ecologically diverse European areas spread over a wide latitudinal gradient.

\section{STUDY AREA AND METHODS}

\section{Data collection}

From 2003 to 2012 we marked 95 juveniles (from 23 nests) in Spain with conventional units (Biotrack, http://www.biotrack.co.uk; for details on study area and radiotracking procedure see Delgado et al. 2010, Penteriani and Delgado 2011) and 24 juveniles (from 18 nests) in Finland with satellites units (Microwave

Telemetry, http://www.microwavetelemetry.com). 24 juveniles (from 17 nests) were marked in Switzerland (for details on the study area and radiotracking procedure see Aebischer et al. 2010, Schaub et al. 2010) with: (i) $30 \mathrm{~g}$ battery-powered satellite transmitters supplied by North Star (http://www.northstarst.com); and (ii) 15 g VHF tags (Holohil, http://www.holohil.com). The weight of the transmitters was between the 3 and the $3.5 \%$ of the weight of the smallest individual at the time of tagging (Spain: $850 \mathrm{~g}$, 
mean $\pm S D=1267 \pm 226.4$ g; Finland: $1370 \mathrm{~g}$, mean $\pm S D=1861.2 \pm 283.8 \mathrm{~g}$;

93 Switzerland: 1000 g, mean \pm SD $=1506 \pm 260.9$ g; see also Penteriani et al. 2011). Signals

94 from the satellite transmitters were recorded by the ARGOS satellite system (www.cls.fr).

95 To make comparable the data acquired by different radiotracking equipments and methods, for each individual we estimated the start of dispersal in the same way (Delgado and Penteriani 2008): we defined dispersal as starting when the distance of each location from the nest became larger than the global mean distance travelled to the nest, that is, when the distance of each location from the nest started progressively increasing rather than

100 fluctuating around a low value. Owls were sexed by molecular procedures using DNA

101 extracted from blood samples (Delgado et al. 2010).

Moon phases

103 Over the study years, daily variations of the moon phases were obtained from the Naval

104 Oceanography Portal (http://aa.usno.navy.mil/data/docs/RS_OneYear.php) and expressed

105 in terms of the fraction of moon disk illuminated and whether the moon was waxing or

106 waning. Following the periodic regression approach suggested by deBruyn and Meeuwig

107 (2001) and applied elsewhere (e.g. Kuparinen et al. 2010; Penteriani et al. 2011, 2013), the

108 fraction of moon disk illuminated was converted into radians $(\theta)$, with one lunar cycle

109 corresponding to a gradual change from 0 to $2 \pi$ radians ( 0 and $2 \pi$ radians correspond to

110 the full moon, and $\pi$ radians corresponds to the new moon). $\operatorname{Cos}(\theta), \sin (\theta), \cos (2 \theta)$ and

$111 \sin (2 \theta)$ transformations were included in the statistical model as explanatory variables, to

112 investigate possible lunar effects on eagle owl behaviour throughout the lunar cycle (see

113 deBruyn and Meeuwig 2001, for details). Given that the probability to have a cloudy night

114 is equally distributed over the study period and, consequently, among all moon phases, we 
115 considered such variation to lead to additional noise, which is likely to weaken the signal

116 strength in our results rather than to create systematic biases (Penteriani et al. 2013).

\section{Statistical analyses}

118 To test the effects of moon phase, age (days after hatching) and sex of individuals, as well as

119 the interactions between age and the different moon phases on the decision to start

120 dispersal (as Julian date), we used linear mixed-effects models. We first selected the optimal

121 structure of the random component, which was the one containing three levels of random

122 effects, represented by birthplace nested in country nested in year (ESM1). The response

123 variables were scaled, i.e. normalised to zero mean and unit variance. Model simplification

124 was performed by backward selection of variables from the full model, and models were

125 compared using likelihood ratio tests until a minimal adequate model was obtained

126 (Crawley 2007). An ANOVA test compared age of dispersal among the three countries. All

127 statistical analyses were performed in R 2.10.1 statistical software (R Development Core

128 Team 2009), nlme (Pinheiro et al. 2009) package.

\section{$130 \quad$ RESULTS}

131 Mean age of dispersal $( \pm S D)$ was $163.6 \pm 20.1$ days, (range $=116-222$ days), not differing significantly $\left(\mathrm{F}_{2,140}=2.40, \mathrm{P}=0.10\right)$ between Spain $($ mean $=166.8 \pm 20.1$ days, range $=$ $128-222$ days), Finland (mean $=150.0 \pm 18.6$ days, range $=116-185$ days $)$, and

134 Switzerland $($ mean $=164.1 \pm 16.6$ days, range $=140-209$ days $)$.

136 decision to start dispersal was influenced by: $(i)$ age of individuals, i.e. dispersal mainly

137 started when juveniles were -6 months old; ( $i i)$ sex, with males (age of dispersal $=161.3 \pm$ 
13822.1 days, range $=116-222$ days) showing more variation in their departure age than

139 females (age of dispersal $=166.6 \pm 16.9$ days, range $=127-206$ days); (iii) the moon

140 phase, with dispersal departures mostly occurring during a full moon (Fig. 1); and (iv) the

141 interaction between age and moon phase: the moonlight effect was the highest when owls

142 dispersed at the average dispersal age of this species.

144 DISCUSSION

145 Dispersal age appears to be a constant trait of eagle owl life-history: most departures

146 occurred in a relatively narrow time window, despite the diverse ecological conditions and

147 wide latitudinal gradient in this study (from Mediterranean to boreal habitats). Yet, most

148 juveniles approaching dispersal age preferred to initiate dispersal when most of the lunar

149 disc was illuminated. However, when individuals are not able to disperse within that

150 favourable temporal window, they cannot pay much attention to the environmental

151 conditions under which to initiate dispersal. Despite the importance of age specific

152 dispersal, this latter has been ignored in most of the evolutionary theory of dispersal (Johst

153 and Brandl 2000). In an evolutionary context, the evolution of age specific dispersal

154 strategies may be due to an increase in the efficiency of dispersal at certain age classes (Johst

155 and Brandl 2000). Actually, within the life cycle, timing of dispersal may influence the

156 evolution of dispersal strategies and can be important in predicting the favoured dispersal

157 strategies (Johst and Brandl 1997). One common advantage driving all juveniles of a same

158 species to disperse as soon as they are ready (i.e., at the same age) is the increased access to

159 higher quality breeding sites: the rapid acquisition of an area where to settle is likely to be

160 especially important in resident, territorial birds, principally if residence is determined by 
161 order of arrival (Ellsworth and Belthoff 1999). Though the proximate factors that stimulate

162 juveniles to initiate dispersal are not well understood, either exogenous or endogenous

163 factors may influence the timing of dispersal (Belthoff and Dufty 1998). Several behaviours

164 have been suggested to appear as the post-fledging period progresses, e.g. parental

165 aggression towards young (Bunn et al. 1982; Wiggett and Boag 1993), aggression of young

166 toward each other (De Laet 1985; Strickland 1991) and decreasing food availability within

167 the natal area (Veltman 1989; Kenward et al. 1993). Despite evidence that exogenous

168 factors may drive dispersal, in some birds neither diminishing food supplies nor parental

169 aggression elicited dispersal, dispersal being mostly initiated by endogenous mechanisms

170 (Nilsson 1990; Belthoff and Dufty 1998). For example, body condition or social status

171 have been considered to play a role in triggering dispersal (Nilsson and Smith 1985;

172 Ellsworth and Belthoff 1999). In two owl species, the western Otus kennicottii and the

173 eastern Otus asio screech-owls, the action of a specific hormone, the adrenal glucocorticoid

174 corticosterone, seems to be responsible of increasing activity levels and changes in body

175 condition (see also Silverin 1997; Wingfield and Ramenofsky 1997), which ultimately

176 trigger juvenile dispersal (Ritchison et al. 1992; Belthoff and Dufty 1995, 1998). That is,

177 exogenous stimuli related to the termination of parental feeding, increased aggression

178 among siblings or other factors may not be required for dispersal departure to start, a

179 hypothesis which is supported by the evidence that eagle owls under different exogenous

180 stimuli started dispersal at the same age. However, the interaction between endogenous and

181 external stimuli at the origin of dispersal initiation demonstrates that the dispersal of eagle

182 owls provides a good example of an ecological process modulated by the combination of 
183 internal and environmentally determined behaviours, which have evolved to fit within the

184 natural geophysical periods (Brown 1972).

185 Because light and dark cycles have existed throughout evolutionary time, many

186 organisms have evolved behaviours that are cued by moon cycles. Indeed, this is not the

187 first time that animal movements have shown an association with moon phases. Increased

188 lunar illumination can increase: (a) swimming depth of pelagic sharks and seals in response

189 to changes in the vertical distribution of their prey related to the aforementioned

190 illumination (e.g. Trillmich and Mohren 1981; Saunders et al. 2011); (b) fish migrations

191 given that they may utilize moonlight to navigate and relocate themselves more easily (e.g.,

192 Leatherland 1992; Hasegawa 2012); (c) dispersal and migration movements in some insects

193 and crustaceans, which may use the moon for vision, orientation and navigation (e.g.

194 Danthanarayana 1986; Scapini et al. 1997); (d) perceptual abilities of dispersing rodents

195 (Zollner and Lima 1999); (e) locomotor activity in owl monkeys of the genus Aotus

196 (Fernández-Duque et al. 2010); and (f) nocturnal bird migrations (e.g., Richardson 1978;

197 James 2000). In the case of eagle owls, we consider plausible the possibility that starting

198 dispersal during the brightest nights increases the perceptual range of dispersers (Zollner

199 and Lima 1997), helping inexperienced juveniles deal with unfamiliar habitats and find

200 prey. Actually, the potential for owls to detect prey increases with increasing light levels

201 (e.g. Clarke 1983; Kotler et al. 1991), which could be crucial for juvenile survival in the

202 days immediately following departure from the natal area. Furthermore, moonlight

203 intensity (due to moon phases) and the time during which the moon is visible in the night

204 sky are correlated (i.e. the nights are brighter for longer), which might represent an

205 additional advantage for individuals to disperse during full moon. Lunar light can thus be 
considered both an environmental condition that is as important as diurnal light and a

207 resource, similar to time, space and temperature (Gerrish et al. 2009).

209 changes owing to the lunar cycle, with predators adjusting their activity rhythms and

210 strategies in response to the increased concealment of prey during the brightest nights

211 (Mukherjee et al. 2009; Kotler et al. 2010; Penteriani et al. 2011). In view of the current

212 results, the lunar cycle might also have the potential to influence predator-prey

213 relationships on a seasonal basis. If, as we may expect, other nocturnal predators also take

214 advantage of the lunar light to start dispersal (Zollner and Lima 1997), we might observe

215 an increased number of predators (adults + dispersers) actively moving around the full

216 moon phase after reproductions. This phenomenon could in turn increase overall predation

217 risk and pressure, exerting a temporally short but profound influence on predator-prey

218 dynamics.

219

Acknowledgements - A special thanks to an anonymous referee and Hannu Pietiäinen, who helped

us to improve the manuscript, and Heikki Lokki and Jyrki Savolainen who helped during

222

fieldwork. The Spanish Ministry of Economy and Competitiveness (CGL2012-33240, FEDER co-

financing), Junta de Andalucía (Excellence Project, RNM-5090), and Swiss MAVA Foundation

224 funded this study. MD and AK received postdoctoral grants ( $\left.\mathrm{n}^{\circ} 140367, \mathrm{n}^{\circ} 132828\right)$ from the

225 Academy of Finland.

226

227 Ethical standards. We manipulated and marked owls under: (i) Spanish Junta de

228 Andalucía-Consejería de Medio Ambiente authorizations No. SCFFS-AFR/GGG RS- 
230 Development, Transport and Environment; and (iii) Swiss Federal Office for the

231 Environment.

232

\section{REFERENCE LIST}

234 Aebischer A, Nyffeler P, Arlettaz R (2010) Wide-range dispersal in juvenile Eagle Owls (Bubo bubo) across the European Alps calls for transnational conservation programmes. J Ornithol 151:1-9

Belthoff JR, Dufty AM Jr (1995) Locomotor activity levels and the dispersal of western screechowls, Otus kennicottii. Anim Behav 50:558-561

Belthoff JR, Dufty AM Jr (1998) Corticosterone, body condition and locomotor activity: a model for dispersal in screech-owls. Anim Behav 55:405-415

Bonte D, Van Dyck H, Bullock JM, Coulon A, Delgado MM et al. (2012) Costs of dispersal. Biol Rev 87:290-312

Brigham RM, Barclay RMR (1992) Lunar influence on foraging and nesting activity of common whippoorwills (Phalaenoptilus nuttallii). Auk 109:315-320

245 Brown FA (1972) Clocks timing biological rhythms. Am Sci 60:756-766

Bulyuk VN, Mukhin A, Kishkinev D, Kosarev V (2009) To what extent do environmental factors affect the long-distance nocturnal post-fledging movements of the Reed Warbler? J Ornithol 150:339-350 
250 Clarke JA (1983) Moonlights influence on predator prey interactions between short-eared owls (Asio flammeus) and deermice (Peromyscus maniculatus). Behav Ecol Sociobiol $13: 205-209$

253 Crawley MJ (2007) The R Book. John Wiley \& Sons, Ltd., Chichester

254 Danthanarayana W (1986) Lunar periodicity of insect flight and migration. In: Danthanarayana W (ed) Insect flight: dispersal and migration. Springer-Verlag, Berlin, pp 88-119

257

de Laet JV (1985) Dominance and aggression in juvenile great tits, Parus major major L. in relation to dispersal. In: Sibly RM, Smith RH (eds) Behavioral ecology: ecological consequences of adaptive behavior. Blackwell Scientific, Oxford, pp 375-380

deBruyn AMH, Meeuwig JJ (2001) Detecting lunar cycles in marine ecology: periodic regression versus categorical ANOVA. Mar Ecol Progr Ser 214:307-310

Delgado MM, Penteriani V (2008) Behavioral states help translate dispersal movements into spatial distribution patterns of floaters. Am Nat 172:475-485

Delgado MM, Penteriani V, Revilla E, Nams VO (2010) The effect of phenotypic traits and external cues on natal dispersal movements. J Anim Ecol 79:620-632

Ellsworth EA, Belthoff JR (1999) Effects of social status on the dispersal behaviour of juvenile western screech-owls. Anim Behav 57:883-892

Fernandez-Duque E, de la Iglesia H, Erkert HG (2010) Moonstruck primates: owl monkeys (Aotus) need moonlight for nocturnal activity in their natural environment. PloS ONE 5: e12572

Gerrish GA, Morin JG, Rivers TJ, Patrawala Z (2009) Darkness as an ecological resource: the role of light in partitioning the nocturnal niche. Oecologia 160:525-536 
Hasegawa EI (2012) Chum salmon Oncorhynchus keta respond to moonlight during homeward migrations. J Fish Biol 81:632-641

James D, Jarry G, Erard C (2000) Influence of the moon on the nocturnal postnuptial migration of the skylark Alauda arvensis L. in France. CR Acad Sci III-Vie 323:215224

Johst K, Brandl R (1997) Evolution of dispersal: the importance of the temporal order of reproduction and dispersal. Proc R Soc Lond B 264:23-30

Johst K, Brandl R (2000) Evolution of age specific dispersal: a general discussion from the standpoint of the invasion fitness concept. Web Ecol 1:82-85

Kenward RE, Marcström V, Karlbom M (1993) Post-nesting behaviour in goshawks, Accipiter gentilis: I. The causes of dispersal. Anim Behav 46:365-370

Kotler BP, Brown JS, Hasson O (1991) Factors affecting gerbil foraging behavior and rates of owl predation. Ecology 72:2249-2260

Kotler BP, Brown J, Mukherjee S, Berger-Tal O, Bouskila A (2010) Moonlight avoidance in gerbils reveals a sophisticated interplay among time allocation, vigilance and state-dependent foraging. Proc R Soc Lond B 277:1469-1474

Kuparinen A, Klefoth T, Arlinghaus R (2010) Abiotic and fishing-related correlates of angling catch rates in pike (Esox lucius). Fish Res 105:111-117 Ecol Evol 11:131-135 
Mukherjee S, Zelcer M, Kotler BP (2009) Patch use in time and space for a meso-predator in a risky world. Oecologia 159:661-668

Nilsson J-Ar (1990) Family flock break-up: spontaneous dispersal or parental aggression? Anim Behav 40:1001-1003

Nilsson J-Ar, Smith HG (1985) Early fledgling mortality and the timing of juvenile dispersal in the marsh tit Parus palustris. Ornis Scand 16:293-298

Penteriani V, Delgado MM (2011) Birthplace-dependent dispersal: are directions of natal dispersal determined a priori? Ecography 34:729-737

Penteriani V, Kuparinen A, Delgado MM, Lourenco R, Campioni L (2011) Individual status, foraging effort and need for conspicuousness shape behavioural responses of a predator to moon phases. Anim Behav 82:413-420

Penteriani V, Kuparinen A, Delgado MM, Palomares F, López-Bao JV et al. (2013) Responses of a top and a meso predator and their prey to moon phases. Oecologia $173: 753-766$

Pienkowski MW (1982) Diet and energy-intake of grey and ringed plovers, Pluvialis squatarola and Charadrius hiaticula, in the non-breeding season. J Zool 197:511549

Pinheiro J, Bates D, DebRoy S, Sarkar D, the R Core team (2009) nlme: Linear and Nonlinear Mixed Effects Models. R package version 3.1-96, http://cran.rproject.org/web/packages/nlme/nlme.pdf

R Development Core Team (2009) R: A language and environment for statistical computing. R Foundation for Statistical Computing, Vienna, Austria. ISBN 3900051-07-0, URL: http://www.R-project.org 
319 Richardson WJ (1978) Timing and amount of bird migration in relation to weather review. Oikos 30:224-272

Ritchison G, Belthoff JR, Sparks EJ (1992) Dispersal restlessness: evidence for innate dispersal by juvenile eastern screech-owls? Anim Behav 43:57-65

Saunders RA, Royer F, Clarke MW (2011) Winter migration and diving behaviour of porbeagle shark, Lamna nasus, in the Northeast Atlantic. Ices J Mar Sci 68:166-174

Scapini F, Audoglio M, Chelazzi L, Colombini I, Fallaci M (1997) Astronomical, landscape and climatic factors influencing oriented movements of Talitrus saltator in nature. Mar Biol 128:63-72

Schaub M, Aebischer A, Gimenez O, Berger S, Arlettaz R (2010) Massive immigration balances high anthropogenic mortality in a stable eagle owl population: lessons for conservation. Conserv Biol 143:1911-1918

Silverin B (1997) The stress response and autumn dispersal in willow tits. Anim Behav $53: 451-459$

Strickland D (1991) Juvenile dispersal in gray jays: dominant brood member expels siblings from natal territory. Can J Zool 69:2935-2945

Trillmich F, Mohren W (1981) Effects of the lunar cycle on the galapagos fur-seal, Arctocephalus galapagoensis. Oecologia 48:85-92

Veltman CJ (1989) Effects of experimental food addition on post-natal dispersal, polygyny, and reproductive success in pair-defended territories of the Australian magpie

340 Wiggett DR, Boag DA (1993) The proximate causes of male-biased natal emigration in Columbian ground squirrels. Can J Zool 71:204-218 
342 Wingfield JC, Ramenofsky M (1997) Corticosterone and facultative dispersal in response to unpredictable events. Ardea 85:155-166

344 Zollner PA, Lima SL (1997) Landscape-level perceptual abilities in white-footed mice: perceptual range and the detection of forested habitat. Oikos 80:51-60

346 Zollner PA, Lima SL (1999) Illumination and the perception of remote habitat patches by white-footed mice. Anim Behav 58:489-500

348 Zollner PA, Lima SL (1999) Search strategies for landscape-level interpatch movements. Ecology 80:1019-1030

350

351 
352 TABLE 1 The linear mixed-effects model showing the effect of moon phase, age and sex of 353 individuals on the decision to start dispersal

354

355

Value

SE

df

$\mathrm{P}$

356 Intercept

264.63

8.28

$65 \quad 31.96<0.001$

357 age

20.65

0.99

$\begin{array}{lll}62 & 20.79<0.001\end{array}$

358 sex 2

$-2.05$

0.81

$62 \quad-2.54$

0.014

$359 \quad \mathrm{I}(\cos (\mathrm{rad}))$

$-2.23$

1.23

$62-1.81$

0.074

360 age:I(cos $(\mathrm{rad}))$

$-3.01$

1.13

$62 \quad-2.66$

0.010 
361 FIGURE LEGENDS

362 Fig. 1 Dispersal departures of eagle owls at various moon phases. When individuals reach

363 their dispersal age (see Results), they mainly leave the natal area during bright nights

364 
365 Figure 1

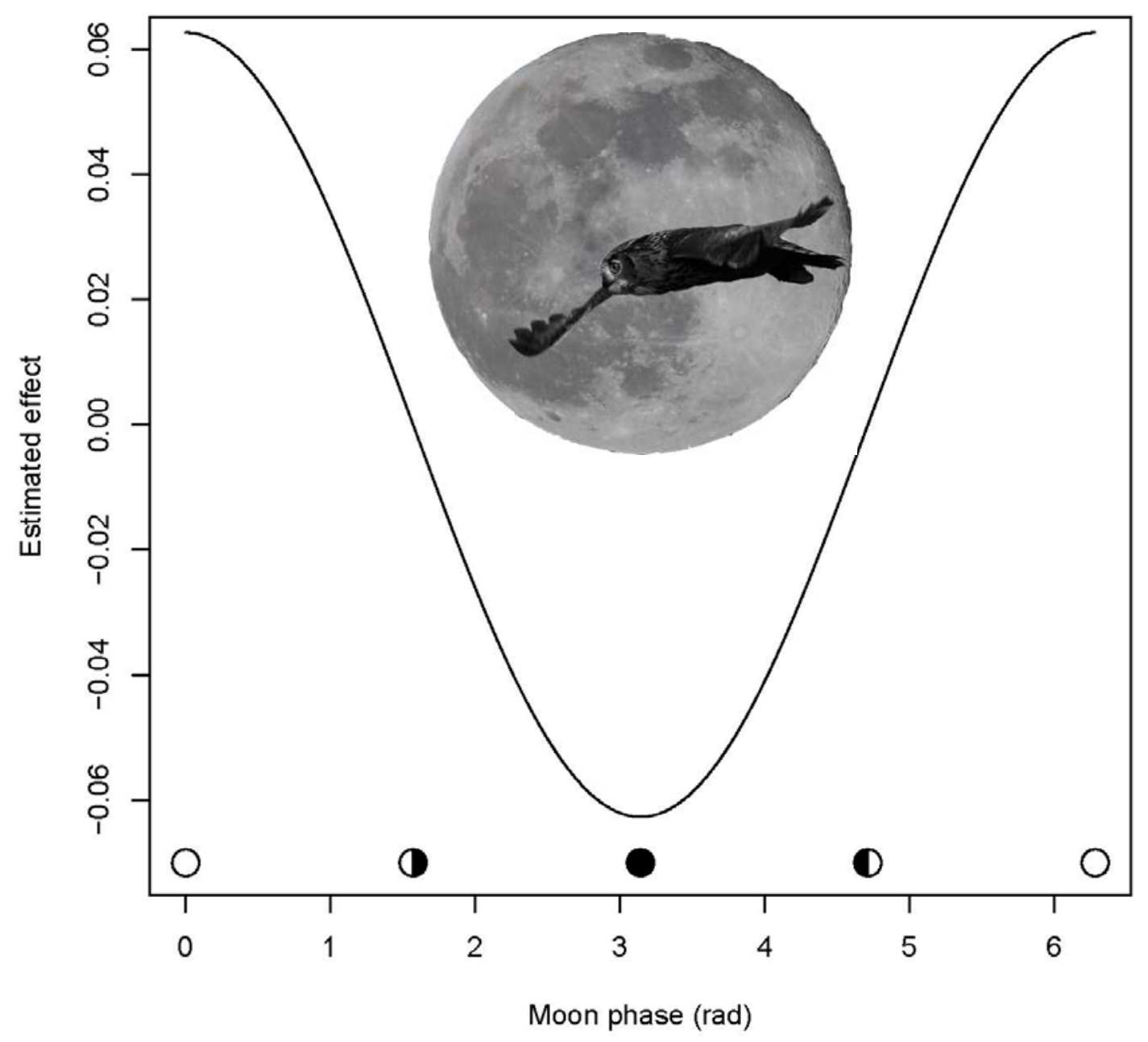

366 